\title{
It was never about The Cancer It was about Me
}

Cite as: CMAJ 2018 July 30;190:E913. doi: 10.1503/cmaj.180539

Crept in quiet, slow

\section{Dysplasia}

Like medieval medicine's earthly humour.

Carelessly and inadvertently sown,

The seedlings were nurtured by potato chips and insomnia

And watered with ethanol.

The glamour of a dream career come true

Concealing the hazards of new-found habits.

Those sleepless nights spent ardently learning

about the very thing making me sick.

\section{Carcinoma in situ}

The student of modern medicine overlooked

Her own symptoms -

Perhaps willfully.

Weight loss, night sweats, pain.

Took a week to believe what the doctor said.

Malignant.

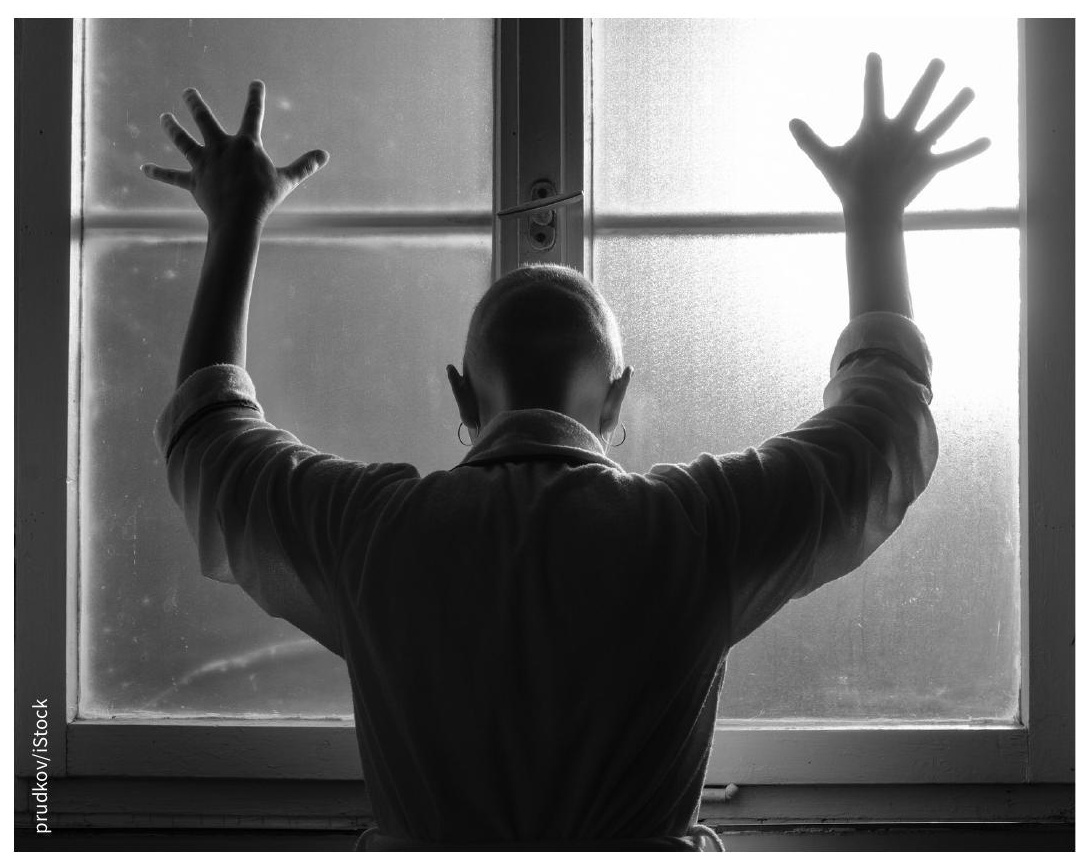

\section{Genetics \{one hit\}}

+ stress $\{$ two hits $\}=$

Not my fault.

The equation of blame remains.

\section{Invasive carcinoma}

It takes a village

To extract the small child's worth of malignancy from my body.

The double-edged blade

Leaves me bleeding and reeling all the same.

Irony is a sick healer,

A toxic treatment.

\section{Dysplasia}

